\title{
Authors' reply to the comment by Shek et al. on: "Descending perineum syndrome: a review of the presentation, diagnosis, and management" by Chaudhry and Tarnay
}

\author{
Christopher M. Tarnay ${ }^{1} \cdot$ Zaid Chaudhry $^{1}$ \\ Published online: 17 November 2016 \\ (C) The International Urogynecological Association 2016
}

Sir,

We thank Dr. Shek and colleagues for their interest in our review on descending perineal syndrome (DPS), as well as for their comments and consideration of our article. With regard to the 'alternate hypothesis' proposed by Shek et al., we do concur that the pathophysiology of the condition is indeed associated with the levator hiatus and logically intimately linked to the levator ani complex. Reclassifying DPS as an epiphenomenon is also thought-provoking. Certainly there are several 'syndromes' in medicine whose nomenclature should probably be revisited as our understanding of the conditions evolves. However, we are not convinced that this applies to DPS.

Historically, the use of the term 'syndrome' was first applied to the condition of descending perineum by Parks et al. in 1966 [1]. They acknowledged that the term was "not a wholly satisfactory title" but continued that the term "is descriptive, as perineal descent on straining is both the cause of the symptomatology and the most obvious physical sign." We believe 50 years later that the term 'syndrome' is still apropos. This is particularly true if we are trying to be precise, given that the definition of 'epiphenomenon' ("A symptom

This reply refers to the comment available at doi:10.1007/s00192-0163190-6.

Christopher M. Tarnay

ctarnay@mednet.ucla.edu

1 Female Pelvic Medicine \& Reconstructive Surgery, Ronald Reagan UCLA Medical Center, David Geffen School of Medicine at UCLA, 100 Medical Plaza, Suite 383, Los Angeles, CA 90095, USA appearing during the course of a disease, not of usual occurrence, and not necessarily associated with the disease" [2]) does not appear to be applicable or additive to 'syndrome'.

DPS is not just a 'hypermobile perineum'. As we describe in the review, DPS includes both the sign of a bulging perineum and associated symptoms of obstructed defecation. This said, women suffering with the challenges of DPS have had to date limited therapeutic options. Our practice of offering laparoscopic colpoperineopexy has offered some relief but has not been a panacea. We too await and we are hopeful of the results of the forthcoming surgical trials in women with levator avulsions.

\section{References}

1. Parks AG, Porter NH, Hardcastle J. The syndrome of the descending perineum. Proc R Soc Med. 1966;59:477-482.

2. Farlex Partner Medical Dictionary. 2012. http://medicaldictionary.thefreedictionary.com/epiphenomenon. Accessed 24 Oct 2016. 